\title{
ANTI-QUORUM SENSING POTENTIAL OF LIMONIA ACIDISSIMA (L.) AGAINST VIBRIO HARVEYI KUMB-VA4
}

\begin{abstract}
SRINIVASAN P ${ }^{1 *}$, RAJALAKSHMI M $^{2}$, DINESH KUMAR $\mathbf{S}^{1}$
${ }^{1}$ Aquaculture and Molecular Microbiology Laboratory, Department of Microbiology, Karpagam Academy of Higher Education (Deemed to be University), Coimbatore - 641 021, Tamil Nadu, India. ${ }^{2}$ Department of Bioscience and Research, Shri Nehru Maha Vidyalaya College of Arts and Science, Coimbatore - 641 050, Tamil Nadu, India. Email: srini2k8@gmail.com
\end{abstract}

Received: 02 November 2017, Revised and Accepted: 09 December 2017

ABSTRACT

Objective: This study aims to investigate the quorum-sensing inhibition (QSI) potential of Limonia acidissima L. against the biofilm forming Vibrio harveyi isolated from freshwater fish.

Methods: The present study evaluated the anti-QS activity of the L. acidissima methanol and ethyl acetate (LA-M and LA-EA) fruit extracts using Chromobacterium violaceum ATCC 12472 (wild) and C. violaceum CV026 (mutant) as biomonitor strains and biofilm formation using the crystal violet assay. Vibrio sp. were isolated from freshwater-cultured fishes and screened for biofilm formation property. Strong biofilm forming isolate were subjected to molecular characterization. Limonia fruit pulp was subjected to methanol and ethyl acetate extraction using cold percolation method and yield was calculated. In parallel to determining the QSI properties of the extract, minimum inhibitory concentration (MIC), biofilm inhibition concentration (BIC), antibiofilm properties, and metabolic activity of LA-M and LA-EA against the biofilm forming $V$. harveyi KUMB-VA4 was determined.

Results: The results of the present study demonstrated that the overall yield of methanol and ethyl acetate extract was $12.84 \%$ and $9.3 \%$ (w/w), respectively. Strong biofilm forming Vibrio isolate KUMB-VA4 was obtained from infected freshwater fishes and was subjected to molecular characterization. MIC of LA-M was $1510 \mu \mathrm{g} / \mathrm{ml}$ and LA-EA was observed to be $3000 \mu \mathrm{g} / \mathrm{ml}$ against the test pathogen, respectively. Biofilm inhibition assay revealed a BIC of LA-M at $250 \mu \mathrm{g} / \mathrm{ml}$ and LA-EA at $500 \mu \mathrm{g} / \mathrm{ml}$. Both the plant extracts significantly reduced the biofilm formation of $V$. harveyi KUMB-VA4 and the metabolic activity in a dose-dependent manner. Light microscopy and scanning electron microscopy revealed that LA-M and LA-EA significantly altered $68.6 \%$ and $54.5 \%$ of the biofilm architecture at BIC. The QSI assay revealed that LA-M effectively reduced the violacein production of the biomonitor strains at sub-BIC (100-500 $\mu \mathrm{g} / \mathrm{ml})$ to $80 \%$ than LA-EA (43\%) in a strong dose-dependent fashion.

Conclusions: The present study revealed the QSI property of Limonia acidissima against the biofilm forming $V$. harveyi isolated from infected fish.

Keywords: Limonia acidissima, Vibrio harveyi, Chromobacterium violaceum, Quorum-sensing inhibition.

(C) 2018 The Authors. Published by Innovare Academic Sciences Pvt Ltd. This is an open access article under the CC BY license (http://creativecommons. org/licenses/by/4. 0/) DOI: http://dx.doi.org/10.22159/ajpcr.2018.v11i3.23448

\section{INTRODUCTION}

The genus Vibrio and their closely related species are significant pathogens affecting the intensive rearing of finfish, molluscs, and shrimps [1]. Traditionally, antibiotics are used to control bacterial diseases in aquaculture sector. However, the frequent application, in many cases even as preventive measures, has resulted in the development and spread of resistance among the bacterial pathogens [2]. Vibrios are Gram-negative, rod-shaped bacteria, but they may also be curved or comma-shaped. They are non-sporulating, non-capsulated, facultative anaerobes, catalase-positive, and motile by means of a single polar flagellum [3]. In fish, the diseases include vasculitis, gastroenteritis, and eye lesions. With shrimp, the pathogen is associated with luminous vibriosis. Clinical signs of vibriosis are hemorrhage to intestines, body cavity, spleen and muscle, distended mucoid and necrotic intestine and petechiation, erosion and darkened coloration to the skin and fins. Changes to the eyes include distension and cloudiness and periorbital swelling. White/gray lesions can be found on the intestines and spleen and in fry, splenomegaly.

Decades of research has enabled the recognition of bacterial biofilms as the predominant bacterial survival tactics [4]. Biofilms play a vital role in the fouling process [5] and are known to have astounding rate of tenacious antibiotic resistance [6], one of the dominant obstacles in the antimicrobial chemotherapy. The pathogenicity mechanisms of Vibrio are imprecisely understood, with likely mechanisms involving the ability to attach and form biofilms, quorum sensing (QS), various extracellular products including proteases and hemolysins, lipopolysaccharide, and interaction with bacteriophage and bacteriocin-like substances [7]. QS, or bacterial cell-to-cell communication, is a key process for bacterial colonization of substrata through biofilm formation, infections, and production of virulence factors. It involves the regulation of coordinated behaviors in bacteria as a function of population density which is achieved by the production, excretion, and detection of autoinducer (AI) molecules [8]. These AI molecules trigger the QS mechanism which aids the bacteria to optimize their energy metabolism and regulate its characteristic functions such as biofilm formation and expression of virulence factors. Biofilm formation by Vibrio sp. enhance the development of antibiotic resistance and sometimes the synthesis of bioluminescence pigment [9]. With the rapid developments in aquaculture, particularly in Asia, the organism has become a serious cause of disease in fish. Study on the QS inhibitors (QSIs) has gained prominence as the QSIs do not exert a selective pressure on the bacterial population and growth thereby successfully avoid the development of resistance toward antibiotic treatments [10]. Moreover, reports elucidate that QS signaling molecules interact directly with the biofilm forming bacterial colonies [11] and so QS disruption, directly or indirectly prevents the biofilm formation on underwater surfaces and 
colonization of fish larvae $[12,13]$. Accordingly, the search for effective and QSIs has gained importance for research in herbal biomedicine, aquaculture and other fields where bacterial biofilms are causes of sanitary problems.

Natural products are vital sources of QSIs that can potentially inhibit QS mechanism. The presence of such compounds in medicinal plants is extremely interesting because, in most cases, medicinal plants are non-toxic to humans and readily available $[14,15]$. A wide variety of medicinal plants and their derived compounds have been reported in terms of structural diversity and biological activity as an effective inhibitors of not only the biofilm formation but also virulence factors in pathogens by interfering with QS mechanism in various pathogens $[16,17]$. Spices such as garlic, ginger, and turmeric have been reported for their QSI potential [18]. Similarly, the essential oils of cinnamon [19] and clove [20] are also known to possess QSI potentials. Moreover, the antibiofilm potential of Indian medicinal plants such as Leucas aspera (Lamiaceae), Vitex negundo (Verbenaceae), Piper longum, and Piper nigrum (Piperaceae) against biofilm-forming pathogens has been well established [21,22].

Limonia acidissima (Rutaceae), a traditional Indian medicinal plant used to treat blood impurities, leukorrhea and urinary problem. The plant belongs to a monotypic genus and is indigenous to Indian subcontinent. Recent study showed the presence of essential amino acids in the fruits of L. acidissima (common name-vilam palam) and its rich antioxidant potential Darsini et al. [23]. The fruit of L. acidissima has been evaluated for enhancing the immunity of freshwater fish fingerlings under in vitro conditions. The immunostimulatory potential of L. acidissima fruit as a feed supplement for freshwater fishes have elucidated increased growth, immunity, and survival of fishes against Aeromonas hydrophila infection [24]. In addition, research has substantiated the anti-biofilm potential of L. acidissima fruit against the biofilm forming A. hydrophila isolated from infected freshwater fishes [25]. The present study has been focused on the antibiofilm potential of L. acidissima on the biofilmforming Vibrio sp.

\section{METHODS}

\section{Sample collection}

Samples were collected randomly from freshwater fishes cultured in and around Coimbatore, Tamil Nadu, India. The source of sample collection is represented in Table 1. Lesions from skin, gills, and scales of infected fishes were cut at $3 \mathrm{~mm}$ (diameter) using sterile scalpel. The cut tissues were resuspended in sterile $1 \times$ phosphate buffered saline (PBS, pH 8.2) and stored at $4^{\circ} \mathrm{C}$ until further use.

\section{Bacterial strains}

The tissue samples were taken and partially homogenized using microfuge tube tissue homogenizer (Tarsons, India). From this, samples were aseptically inoculated using spread plate technique on to thiosulfate citrate bile sucrose (TCBS) agar plates (Himedia, India). After inoculation, the plates were incubated at $37^{\circ} \mathrm{C}$ for $24 \mathrm{~h}$. The isolates were then subcultured in nutrient broth (NB) (Himedia, India) for routine use. Glycerol stock was maintained at $-20^{\circ} \mathrm{C}$ for longterm usage. Reporter strain Chromobacterium violaceum ATCC 12472 (wild type) and C. violaceum CV026 (mutant) were used to test the QSI potential of the plant extracts. Both the strains were cultured in LuriaBertani (LB) broth at $35^{\circ} \mathrm{C}$.

\section{Characterization of bacterial isolates}

The isolates were subjected to morphological characterization by media culture and microscopic morphology using Gram's stain. Motility was determined by microscopic examination of a hanging drop of NB culture incubated for $24 \mathrm{~h}$ at $37^{\circ} \mathrm{C}$ [26]. Biochemical tests included oxidase test, catalase test $\left(\mathrm{H}_{2} \mathrm{O}_{2} 5 \%\right)$, citrate utilization test, indole production test, hydrogen sulfide production test, MR-VP test, and carbohydrate fermentation test $(1 \% \mathrm{w} / \mathrm{v}$ of glucose, xylose, sorbitol, sucrose, and arabinose) [27]. All the isolates were screened for Vibrio sp. and then subjected to further analysis.

\section{Detection of biofilm formation}

The Vibrio sp. Isolates were screened for their ability to form biofilm under static conditions in 24 well microtiter plates (MTPs) by following the method of Darsini et al. [23] with slight modifications. Briefly, $16 \mathrm{~h}$ cultures of isolates were prepared and gently resuspended in $5 \mathrm{ml}$ NB ( $\mathrm{pH} 7.3 \pm 0.2$ ) (Himedia, India) medium and adjusted to an optical density of 1.0 at $620 \mathrm{~nm}$. Then, the bacterial suspensions were aliquoted $(1 \mathrm{ml})$ in each well of polystyrene 24 well MTPs (Tarsons, India) and incubated for up to $48 \mathrm{~h}$ at $37^{\circ} \mathrm{C}$ without shaking. After incubation, the isolates were analyzed for biofilm formation.

The planktonic cells were discarded and attached cells were gently washed twice with PBS, and fixed with glutaraldehyde for $15 \mathrm{~min}$ at room temperature and stained with $0.4 \%(\mathrm{w} / \mathrm{v})$ crystal violet (Himedia, India) for $10 \mathrm{~min}$ at room temperature. Then, the crystal violet stained cells were solubilized with $1 \mathrm{ml}$ of ethanol-acetone solution $(8: 2, v / v)$. The biofilm formation ability was scored as strong $(+++)$, moderate $(++)$, weak $(+)$, and negative $(-)$ by visually comparing the thickness of adherent layer and the results were tabulated. The isolates capable of strong biofilm formation were subjected for further studies.

\section{Molecular characterization of biofilm-forming Vibrios Isolation of genomic DNA}

About $10 \mathrm{ml}$ of bacterial biomass was collected by centrifugation at $10,000 \times g$ for $5 \mathrm{~min}$. The cell pellets were resuspended in $400 \mu \mathrm{l}$ of TE buffer (pH 8.0). Then, the mixture was lysed by adding $200 \mu \mathrm{l}$ lysozyme $(10 \mathrm{mg} / \mathrm{ml})$ and incubated at $37^{\circ} \mathrm{C}$ for $1 \mathrm{~h}$, followed by $40 \mu \mathrm{l}$ of proteinase $\mathrm{K}(10 \mathrm{mg} / \mathrm{ml})$ at room temperature for $10 \mathrm{~min}$. The mixture was then treated with $1 \%$ SDS and incubated at room temperature until the solution turned clear. About, $80 \mu \mathrm{l}$ of $0.5 \mathrm{M}$ EDTA was added, mixed gently and the protein content was removed by sequential phenol: Chloroform: Isoamyl alcohol (24:23:1 v/v) extraction in which the aqueous layer containing the DNA was collected in a separate tube. Equal volume of isopropanol was added to the collected supernatant and centrifuged at $10,000 \times g$ for $10 \mathrm{~min}$, and after centrifugation, $70 \%$ alcohol was used to wash the pellet. The tubes were blot dried and the pellet was dissolved in $500 \mu \mathrm{l}$ TE buffer ( $\mathrm{pH}$ 8.0).

\section{$16 S$ rRNA gene PCR}

The 16S rRNA gene was amplified from the extracted genomic DNA using the $27 \mathrm{~F}$ and $1492 \mathrm{R}$ universal eubacterial primers designed to target the conserved regions in the genomic DNA of the isolates and amplify approximately $1.3 \mathrm{~kb}$ length gene. The forward primer $5^{\prime}$-AGA GTT TGA TCC TGG CTC AG-3' and reverse primer 5'-GGT TAC CTT GTT ACG ACT T-3' (Xcelris Lab Ltd, Ahmedabad, India) were used for amplification [28]. The PCR mix contained $5 \mu \mathrm{l}$ of $10 \times$ PCR buffer, 4 $\mu \mathrm{l}$ of $25 \mathrm{mM} \mathrm{MgCl}, 5 \mu \mathrm{l}$ of $10 \mathrm{pmol} 27 \mathrm{~F}, 5 \mu \mathrm{l}$ of $5 \mu \mathrm{M} 1492 \mathrm{R}, 5 \mu \mathrm{l}$ of $1 \mathrm{mM}$ DNTP's, $0.5 \mu \mathrm{l}$ of Taq DNA polymerase (Thermo Scientific, India), and $2 \mu \mathrm{l}(50 \mathrm{ng})$ of genomic DNA. The reaction volume was adjusted and made up to a final volume of $50 \mu \mathrm{l}$ with sterile double-distilled water and amplified in an automated thermal cycler (Vapo protect Pro S, Eppendorf). The PCR conditions were an initial denaturation stage at $94^{\circ} \mathrm{C}$ for $2 \mathrm{~min}$, followed by 35 cycles of denaturation at $94^{\circ} \mathrm{C}$ for $45 \mathrm{~s}$, annealing at $55^{\circ} \mathrm{C}$ for $60 \mathrm{~s}$, extension at $72^{\circ} \mathrm{C}$ for $60 \mathrm{~s}$, and a final extension step at $72^{\circ} \mathrm{C}$ for $10 \mathrm{~min}$. Negative controls with no DNA template were included in all PCR experiments.

\section{Collection of plant and solvent extraction}

L. acidissima (LA) fruits were obtained from foothills of Vellingiri during December 2016. The fruits were washed and cleaned before processing. The outer shell was broken and the fruit pulp was scooped, shade dried, pulverized, and processed into fine powder. Then, $25 \mathrm{~g}$ of LA powder was soaked in $250 \mathrm{ml}$ of solvents such as methanol (LA-M) and ethyl acetate (LA-EA) (1:4) for $48 \mathrm{~h}$ with constant mixing. Then, the concoction was subjected to cold percolation extraction method. The retentate was reextracted with respective solvents while the filtrate was subjected to rotary vacuum evaporation (Model: R150, Labomed, 
India). The yield of dried extracts was calculated using the following equation,

Yield $(\mathrm{g} / 100 \mathrm{~g}$ of dry plant material $)=\left(\mathrm{W}_{1} \times 100\right) \div \mathrm{W}_{2}$

Where, $\mathrm{W}_{1}$ was the weight of the extract after the evaporation of solvent, and $\mathrm{W}_{2}$ was the weight of the dry plant material.

\section{Effect of LA extracts on the biofilm forming test pathogen Minimum inhibitory concentration (MIC) assay}

The MIC of the LA-M and LA-EA extracts were determined against the test isolates by following the Clinical and Laboratory Standards Institute reference method of MTP assay [29] with slight modifications. Briefly, an overnight culture of Vibrio sp. isolate was subcultured in NB until a turbidity equivalent to 0.5 McFarland standard solutions $\left(1 \times 10^{6} \mathrm{CFU} / \mathrm{ml}\right)$ was obtained.

This bacterial suspension was added to NB supplemented with LA extract serially diluted two-fold to give final concentration ranging from $31.25 \mu \mathrm{g} / \mathrm{ml}$ to $8000 \mu \mathrm{g} / \mathrm{ml}$ and incubated at $37^{\circ} \mathrm{C}$ for $24 \mathrm{~h}$. The MIC was recorded as the lowest concentration, which showed complete inhibition of visible growth. The results were further confirmed spectrophotometrically at $620 \mathrm{~nm}$.

\section{Growth curve analysis}

One percentage of overnight culture of test pathogens (1.0 OD at600 nm) were inoculated in $250 \mathrm{ml}$ conical flask containing $50 \mathrm{ml}$ of LB broth supplemented with LA-M and LA-EA extracts (sub-MIC). The flasks were incubated at the optimum temperature of respective pathogens under $180 \mathrm{rpm}$ in a rotatory shaker. The well density was measured in 96-well Multiplate reader (Biotek, ELx800, India) at every 1 hour interval up to $12 \mathrm{~h}[25]$.

\section{Quantification of biofilm biomass}

The effect of L. acidissima fruit extract treated Vibrio biofilm was performed according to [30], with slight modification. $20 \mu \mathrm{l}$ of L. acidissima solvent extracts with concentrations ranging from $31.25 \mu \mathrm{g} / \mathrm{ml}$ to $2000 \mu \mathrm{g} / \mathrm{ml}$ (Sub-MIC) were incorporated in $1 \mathrm{ml}$ of NB containing $20 \mu \mathrm{l}$ of Vibrio sp. Isolates $\left(1 \times 10^{6} \mathrm{CFU} / \mathrm{ml}\right)$ in 24 well MTP and incubated at $37^{\circ} \mathrm{C}$ for $48 \mathrm{~h}$. After incubation, the biofilm was stained using $0.4 \%(\mathrm{w} / \mathrm{v})$ crystal violet. The subinhibitory concentrations $(0.5$, 0.25 , and 0.125 biofilm inhibition concentration [BIC]) of the solvent extracts were also tested against the biofilms by following the same protocol. Then, the absorbance for each well was measured at $570 \mathrm{~nm}$ in spectrophotometer (Model: ELx800, Biotek, India).

\section{Metabolic activity assay}

The metabolic activity of biofilm cells was determined by assaying the XTT reduction of the test pathogen in the presence and absence of the plant extracts at BIC. Briefly, overnight culture of Vibrio sp. was washed twice with PBS and then incubated with $0.5 \mathrm{mg} / \mathrm{ml} \mathrm{XTT}(2,3$-bis (2-methoxy-4-nitro- 5-sulfophenyl) -5-[(phenylamino) carbonyl]-2Htetrazolium hydroxide; Sigma-Aldrich) and $1 \mathrm{mM}$ menadione (SigmaAldrich) in PBS at $37^{\circ} \mathrm{C}$ for $90 \mathrm{~min}$ under dark condition. Further, absorbance was measured spectrophotometrically at $450 \mathrm{~nm}$ for every $6 \mathrm{~h}$ intervals up to $24 \mathrm{~h}$ [25].

\section{Light microscopic observation of biofilm}

About $1 \%$ overnight culture of the test pathogens were added to 24-well microtiter plates containing $1 \mathrm{ml}$ fresh TSB medium and cover glass of $1 \mathrm{~cm}^{2}$. The wells were then incorporated with different concentrations $(31.25-1000 \mu \mathrm{g} / \mathrm{ml})$ of LA-M and LA-EA extracts. Wells without plant extracts were treated as control. The plates were incubated for $48 \mathrm{~h}$ at $37^{\circ} \mathrm{C}$ and then the cover glasses were rinsed thrice with PBS to remove non-adhered planktonic cells. After rinsing, the cover glasses were stained with $0.4 \%(\mathrm{w} / \mathrm{v})$ Crystal Violet solution for $1 \mathrm{~min}$ and washed with distilled water. Stained cover glasses with biofilms were air-dried and visualized under light microscope at magnification of $\times 400$ (Nikon Eclipse E200, Tokyo, Japan) [31].

\section{Scanning electron microscopy}

The test pathogen was incubated on glass coverslips in LB medium at room temperature. The resulting biofilms were fixed with $2 \%$ glutaraldehyde in $0.1 \mathrm{M}$ cacodylate buffer $(\mathrm{pH} 7.2)$ for $1 \mathrm{~h}$ and then postfixed with $1 \%$ osmium tetroxide in $0.1 \mathrm{M}$ cacodylate buffer $(\mathrm{pH} 7.2)$, dehydrated with ethanol (25-100\%), critical point dried, and spurted with gold-palladium alloy. Samples were examined with a scanning image observing device equipped with an electron microscope (Zeiss, Sigma V) [32].

\section{Detection of QS inhibition by quantification of violacein production}

The QSI properties of the LA solvent extracts were carried out preliminarily using Chromobacterium violaceum ATCC 12472 . The solvent extract which exhibited the QSI property against the reported strain was further tested for the quantification of the violacein reduction using $C$. violaceum (CV026). The effect of LA solvent extracts on reduction of $C$. violaceum CV026 violacein production were quantified by spectrophotometric method according to Choo et al. [33]. Briefly, C. violaceum CV026 inoculated $\left(\mathrm{OD}_{620 \mathrm{~mm}}=0.5\right)$ in $\mathrm{LB}$ broth supplemented with N-hexanoyl-1-homoserine lactone (HHL, Sigma Aldrich) at a working concentration of $5 \mu \mathrm{mol} / \mathrm{ml}$ was taken as control and LB broth incorporated with HHL and LA solvent extracts at different concentrations $(100-500 \mu \mathrm{g} / \mathrm{ml})$. The tubes were further incubated at $35^{\circ} \mathrm{C}$ for $24 \mathrm{~h}$. Following incubation, $1 \mathrm{ml}$ of the culture was centrifuged at $12,000 \mathrm{rpm}$ for $10 \mathrm{~min}$ to precipitate the insoluble violacein. One $\mathrm{ml}$ of DMSO was added to the pellet and the solution was vortexed vigorously for $1 \mathrm{~min}$ to completely dissolve violacein. The solution was then centrifuged at $12,000 \mathrm{rpm}$ for $10 \mathrm{~min}$ to precipitate the cells. The cell-free supernatant was collected and quantified spectrophotometrically (Hitachi U-2900, Japan) at $585 \mathrm{~nm}$.

\section{Statistical analysis}

All experiments were performed in triplicates. The values were expressed as mean \pm standard error. Student's $t$-test was performed to determine the significant difference between the samples using SPSS software version 21.0 (USA). The values were considered statistically significant if $\mathrm{p}<0.5$.

\section{RESULTS}

\section{Characterization of bacterial isolates}

Among the colonies formed in the TCBS agar plates, translucent, raised pinpointed yellow colonies were predominant and were indicative of Vibrio sp. From this, a total of 6 isolates were selected for possible Vibrio colonies (Table 1), based on the morphological characteristics on the TCBS agar medium. The isolates were subjected to physiological and biochemical characterization. The results of the morphological and biochemical tests evidently showed that all 6 isolates were Vibrio sp. (Table 2).

\section{Biofilm forming ability of Vibrio sp. Isolates}

Out of 6 Vibrio sp. isolates, one isolate (VA4) (Fig. 1) formed moderate to strong biofilm which was evident from the thick slimy, dense cell architecture on the glass slides. Two isolates (VB3 and VA5) produced weak biofilm and the remaining isolates showed negative for biofilm formation (Table 3). The strong biofilm forming VA4 strain was subjected to further studies in the presence and absence the plant extracts.

\section{Molecular characterization of the biofilm forming Vibrio}

The results of the $16 \mathrm{~S}$ rRNA gene PCR showed a prominent amplification for $1392 \mathrm{bp}$ when subjected to1 \% agarose gel electrophoresis (Fig. 2a). Phylogenetic analysis revealed that the test pathogen shared $99 \%$ gene 
similarity with Vibrio harveyi with a statistical significance of $\mathrm{p}<0.1$ (Fig. 2b).

\section{Solvent extraction and yield}

The dried L. acidissima fruit powder was subjected to solvent extraction using methanol and ethyl acetate. The resulting filtrate was vacuum evaporated and the yield percentage was calculated. The methanol extract yielded $3.211 \mathrm{~g}(12.84 \%)$ per $25 \mathrm{~g}$ of the dry fruit powder, whereas ethyl acetate $2.316 \mathrm{~g}(9.3 \%) 25 \mathrm{~g}$ of the dry fruit powder.

\section{Effect of $L$. acidissima fruit extracts on test pathogen}

\section{MIC assay}

The MIC of methanol and ethyl acetate extracts of L. acidissima fruit were evaluated against VA4 at a concentration ranging from 31.25$8000 \mu \mathrm{g} / \mathrm{ml}$ using MTP assay. The results showed that the MIC of LA-M was $1510 \mu \mathrm{g} / \mathrm{ml}$, whereas the MIC value of LA-EA was observed to be $3000 \mu \mathrm{g} / \mathrm{ml}$ against the test pathogen. The values were confirmed using the spectrophotometric method at $620 \mathrm{~nm}$ and the results were graphically represented (Fig. 3).

\section{Growth curve analysis}

Analysis on the growth of $V$. harveyi VA 4 planktonic cells was performed in the presence and absence of the LA-M and LA-EA at sub-MIC level to rule out the antibacterial effect of the extracts on the test pathogen. Results elucidated no significant difference between the absorbance values of the untreated and L. acidissima solvent extracts treated samples which was evident from the growth curve observed for $12 \mathrm{~h}$ time space. Furthermore, our results provided an additional information that the L. acidissima solvent extracts did not inhibit the growth of the test pathogen during the initial (log) phase of the growth (Fig. 4).

Table 1: Collection of samples from infected fishes

\begin{tabular}{|c|c|c|}
\hline Host species & Tissue/organ & Place of collection \\
\hline $\begin{array}{l}\text { Oreochromis } \\
\text { mossambicus (Tilapia) }\end{array}$ & Skin lesions & $\begin{array}{l}\text { Fish } \\
\text { reservoir (Ukkadam } \\
\text { lake) }\end{array}$ \\
\hline $\begin{array}{l}\text { Cyprinus } \\
\text { carpio (Common carp) }\end{array}$ & Gills & $\begin{array}{l}\text { Fish farm (Bhavani } \\
\text { Sagar) }\end{array}$ \\
\hline $\begin{array}{l}\text { Cirrhinus } \\
\text { mrigala (Mrigal carp) }\end{array}$ & Skin lesion & Fish farm (Aliyar) \\
\hline
\end{tabular}

Table 2: Morphological and biochemical characterization of biofilm-forming test pathogen

\begin{tabular}{ll}
\hline Test & Vibrio sp. \\
\hline Gram-stain & Negative \\
Colony morphology & Small, light green with dark green \\
TCBS medium & centers; yellow halo \\
& Positive \\
Motility & \\
Biochemical analysis & Positive \\
Cytochrome oxidase & Positive \\
Catalase & Positive \\
Indole & Negative \\
MR & Negative \\
VP positive & Positive \\
Citrate utilization & Negative \\
H2S production & Negative \\
Urease & Positive \\
5\% NaCl & \\
Acid and gas production & Acid and gas \\
Glucose & Negative \\
Xylose & Negative \\
Sorbitol & Acid only \\
Sucrose & Acid only \\
Arabinose &
\end{tabular}

\section{Determination of biofilm inhibitory concentration}

The effect of different concentrations LA-M and LA-EA on the biofilm forming ability of Vibrio sp. VA4 was determined. Interestingly, the LA-M extract showed a pronounced biofilm inhibitory effect, with greater than $50 \%$ inhibition against test pathogens at a concentration of $250 \mu \mathrm{g} / \mathrm{ml}$ (BIC), whereas LA-EA exhibited greater than $50 \%$ biofilm inhibition at a concentration of $500 \mu \mathrm{g} / \mathrm{ml}$ (BIC) (Fig. 5).

\section{Metabolic activity assay}

The effect of L. acidissima solvent extracts on the metabolic activity of $V$. harveyi VA4 was analyzed using the XTT metabolic assay. It was observed that during the initial growth phase $(6 \mathrm{~h})$ the solvent extracts did not hinder the metabolism of the test pathogen which could be elucidated from the absorbance readings of the LA-M and LA-EA treated pathogen as compared to the control (Fig. 6). However, prolonged exposure $(12-96 \mathrm{~h})$ to LA solvent extracts significantly $(\mathrm{p}<0.05)$ reduced the XTT metabolism of $V$. harveyi VA4 which was evident from the reduced absorbance of the treated samples as compared to the respected control. Such reduction could be attributed to the fact that long-term exposure affected the metabolism of test pathogens which in turn prevented the organism from converting the XTT to colored end product as compared to their respective control.

\section{Light microscopic observation of Vibrio sp. biofilms}

Observation of biofilm by light microscopy revealed the biofilm disruption effect of L. acidissima extracts against the biofilms formed by $V$. harveyi VA4 over the matrix material. A thick layer of biofilm was formed over the control coverslips which was evident from the dense color of crystal violet on the biofilm (Fig. 7). However, the biofilms treated with LA-M and LA-EA showed concentrationdependent modification, which was noticeable from the reduction in biofilm architecture of Vibrio with increasing concentration. The light microscopic analysis elucidated that the maximum level of reduction in number of microcolonies was observed at the higher concentrations of LA-M and LA-EA against the test pathogens.

\section{Scanning electron microscopy}

The SEM analysis was performed to study the characteristics of $V$. harveyi VA4 biofilm obtained on the glass coverslips surface at optimal in vitro growth condition in the presence and absence of L. acidissima solvent extracts. Results elucidated smooth surface morphology in the untreated control samples, whereas the LA-M- and LA-EA-treated samples showed rough morphology with inundated surfaces and loosened cell architecture which might be due to the antibiofilm activity of L. acidissima solvent extracts. In both control and treated sample, large mucoid extracellular matrix was observed which could be attributed to the biofilm formation (Fig. 8).

\section{QSI potential of L. acidissima}

As both LA-M and LA-EA extracts showed significant antibiofilm property, they were further screened for anti-QS activity which was assessed from violacein production using C. violaceum CV026. The preliminary screening of LA-M and LA-E showed $82 \%$ and $68 \%$ significant reduction in violacein production as compared to C. violaceum ATCC 12472, respectively (Fig. 9a). Hence, both the

Table 3: Screening of Vibrio sp. isolates for their biofilm forming ability

\begin{tabular}{lll}
\hline Isolates & Source & Biofilm formation \\
\hline VA1 & Lesion on scales & - \\
VU2 & Skin lesions & - \\
VB3 & Lesion on scales & + \\
VA4 & Skin lesions & $++/+++$ \\
VA5 & Lesion on scales & + \\
VU6 & Skin lesions & - \\
\hline -: No biofilm, +: Weak biofilm, ++: Moderate biofilm, +++: Strong biofilm
\end{tabular}


extracts were further tested against C. violaceum CV026. Results elucidated that LA-M and LA-EA exhibited concentration-dependent inhibitory activity, which was evident from reduction in the violacein production with increasing concentration (Fig. 9b). Simultaneously, the antibacterial activity of the LA-M was determined against $C$. violaceum CV26, by turbidimetric method at $600 \mathrm{~nm}$ after $24 \mathrm{~h}$ incubation at applied concentrations of $100-500 \mu \mathrm{g} / \mathrm{ml}$. Results revealed that there was no significant reduction in the growth when compared with that
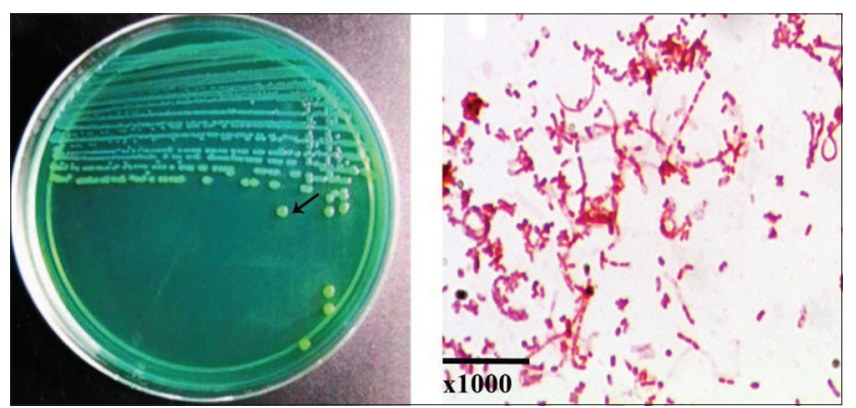

Fig. 1: Characterization of Vibrio sp. VA4 isolate (a) small, light green with yellow halo on thiosulfate citrate bile sucrose agar; (b) Gram-negative curved rods (scale bar $=20 \mu \mathrm{m}$ ) of control (Fig. 9c and d) which indicated that LA-M has no effect on the growth of $C$. violaceum CV026. Therefore, it is considered that LA-M exhibited considerable QSI activity.

\section{DISCUSSION}

In this study, the QSI and antibiofilm efficacy of L. acidissima fruit solvent extracts were evaluated against the biofilm forming $V$. harveyi VA4 at different concentrations (sub-MIC). Although previous study on the antibiofilm efficacy of L. acidissima fruit solvent extracts against the virulent and biofilm-forming fish pathogen A. hydrophila isolate AH1 demonstrated the significant antibiofilm efficacy of this wood apple fruit in disrupting the biofilm formation during the early phase [25], the biofilm-disrupting effect of the LA fruit extracts on the biofilm-forming Vibrio sp. has not been documented previously. Vibrio infections have gained significance in marine and cultured freshwater fish. Vibrio sp. is widespread in diverse habitats and causes infection to warm and coldblooded animals [34]. Potentially, this pathogen can impact the fish yield and produce significant economic losses. Bacterial communities form biofilm by rapid proliferations which are associated with most of the infectious diseases [35]. Vibrio sp. has been widely studied for their biofilm formation and its associated virulence which enable them to proliferate, colonize the surfaces, infect fishes, and reduce fish yield by killing at early stages of their development [36]. Due to the emergence

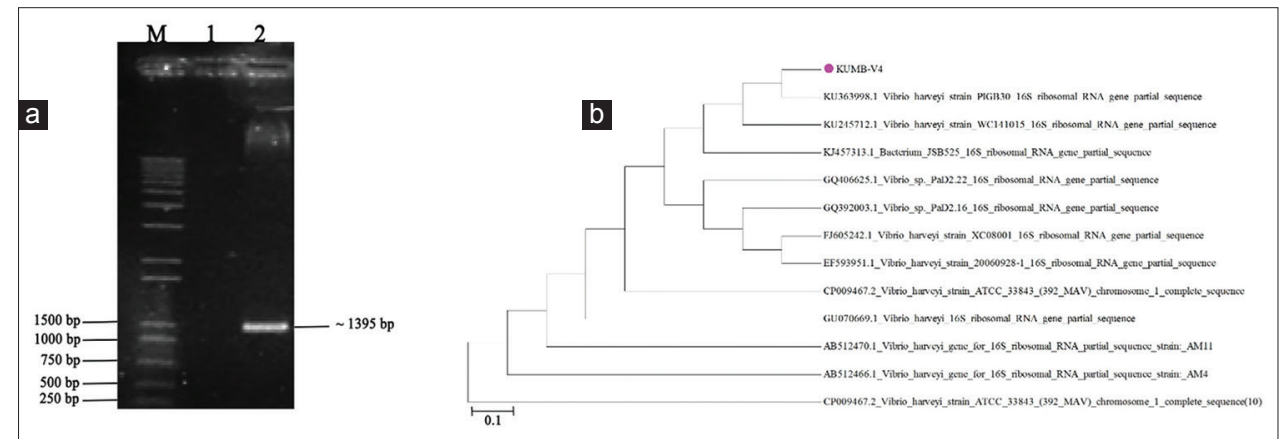

Fig. 2: Molecular characterization of biofilm-forming Vibrio isolate KUMB-VA4 (a) 1\% agarose gel representing 16S rRNA gene amplification (M- 1Kb ladder; Lane 1 - Negative control; Lane 2 - 16S rRNA amplicon of VA4) and (b) Phylogenetic tree of 16S rRNA gene representing the similarity between the test pathogen and standard $V$. harveyi strains

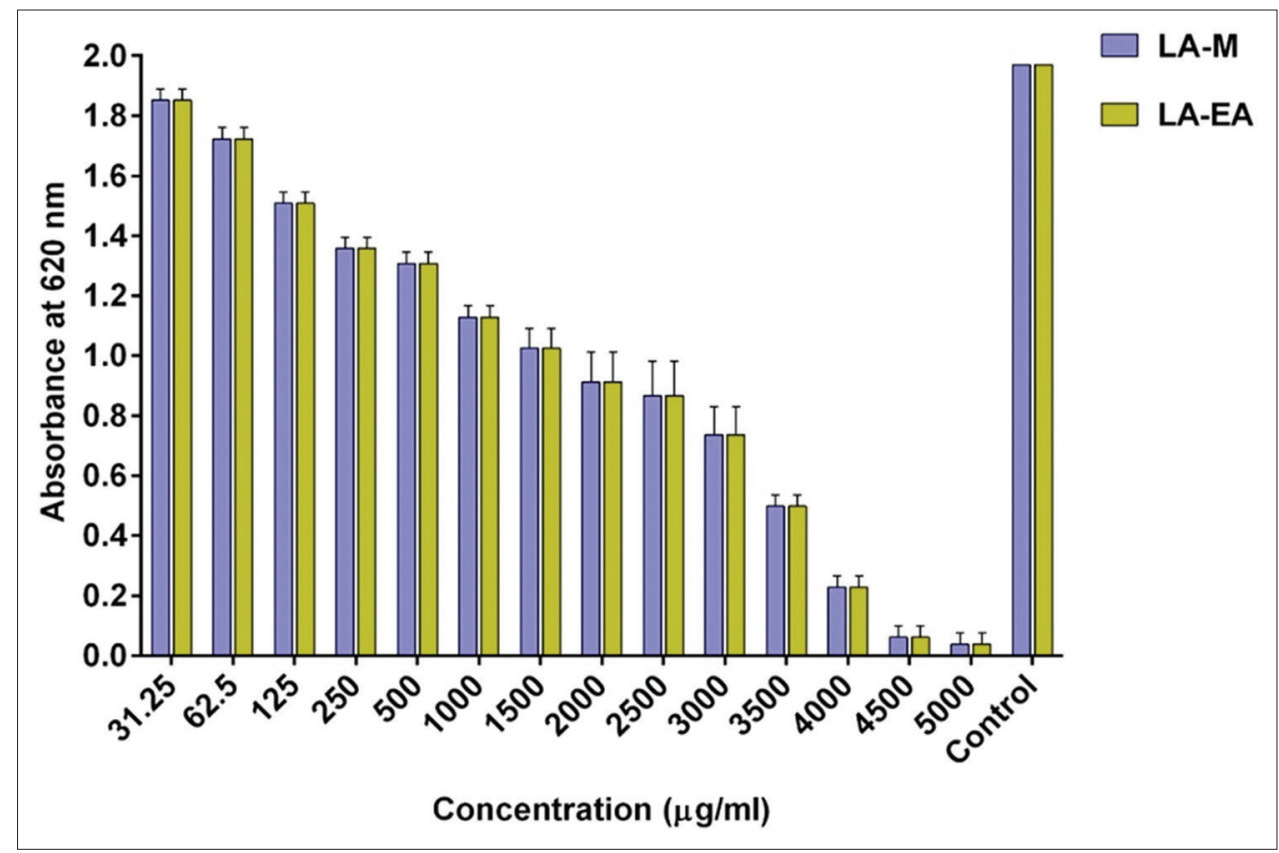

Figure 3: Minimum inhibitory concentration assay of LA-M and LA-EA against biofilm forming Vibrio harveyi VA4. Values are represented as mean \pm standard error of independent biological triplicate experiments 
of drug resistance in Vibrio biofilms, the need for an alternative medicine with low toxicity and side effects has become essential. Medicinal plants constitute as an alternative source for antibiotics with low side effects. It has also been found that bacteria living in the biofilm mode of growth are often up to 1000 times more resistant to antibiotic than their planktonic counterparts [37]. Several studies have elucidated the role of medicinal plants and derived compounds against Vibrio sp. planktonic cells [30]. However, relatively few studies have been conducted on the effect of herbal plants against Vibrio biofilms. L. acidissima plant is known for its significant medicinal properties such as antioxidant [23], antibacterial [38], hepatoprotective [39], and antiinflammatory [40] activity.

Among 6 isolates of Vibrio sp. VB3, VA4, and VA5 showed biofilmforming potential (Table 3). Interestingly, the isolate VA4 exhibited moderate to strong biofilm forming characteristics. Strong biofilm forming potential plays an important role in the establishment of infection, enhanced pathogenesis, and drug resistance [30]. Molecular characterization of the strong biofilm forming isolate VA4 using $16 \mathrm{~S}$ rRNA gene amplification revealed the pathogen as $V$. harveyi. Our results substantiated the prevalence of $V$. harveyi among the cultured freshwater fishes. Mishra et al. [41] also reported the prevalence of $V$. harveyi in the cultured freshwater fishes and prawns in India.

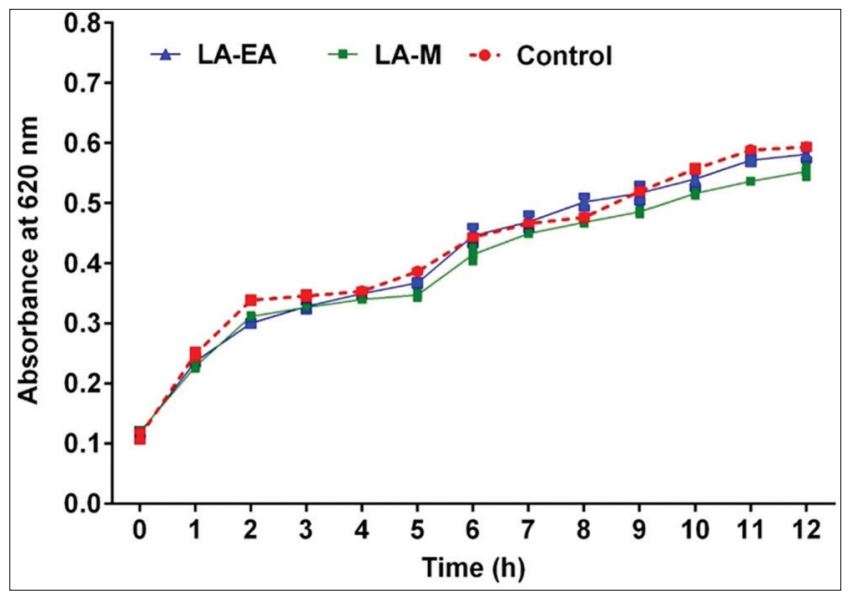

Fig. 4: Growth curve analysis of Vibrio harveyi VA4 planktonic cells treated using random sub-minimum inhibitory concentration of LA-M and LA-EA extracts compared to the untreated control. Values are represented as mean \pm standard error of independent biological triplicate experiments

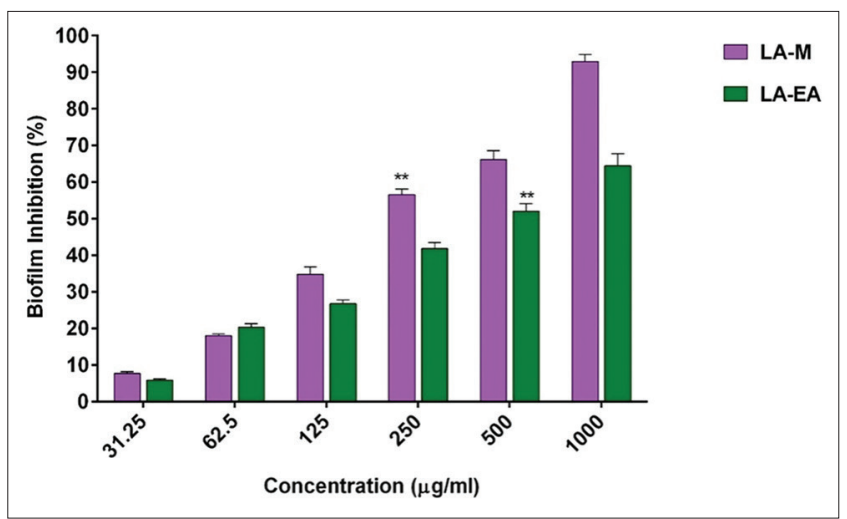

Fig. 5: Biofilm inhibitory concentration percentage of LA-M and LA-EA against biofilm forming Vibrio harveyi VA4. Values are represented as mean \pm standard error of independent biological triplicate experiments. ${ }^{* *} \mathbf{p}<0.01$ significantly different as compared to the control with $\geq 50 \%$ biofilm inhibition
The minimal inhibitory concentrations for the L. acidissima solvent extracts showed prominent inhibitory activity against VA4 at lower concentrations. Further, the antibacterial property of the L. acidissima solvent extracts were ruled out by studying the growth curve of the planktonic cells in the presence and absence of the extracts which showed that the extracts were not bactericidal at the tested sub-MIC level. In continuation of the results obtained from the MIC assays, L. acidissima extracts were further studied, for its ability to alter Vibrio biofilm formation. Interestingly, the biofilm formation was reduced in the presence of LA extracts in a dose-dependent manner. Moreover, the solvent extracts significantly modified the metabolic rate of the test pathogen which evidently showed that at BIC the solvent extracts of L. acidissima were not only disrupting the biofilm formation but also modifying the metabolism of the cells. Decrease in the XTT reduction could be correlated to the decreased metabolic rate of the organism and alteration in the enzyme process of the microorganism [42].

It was also observed that the plant extract treated samples showed significant difference in the biomass inhibition as compared to their respective untreated control. In addition, this study elucidated that LA-M showed significant BIC as compared to LA-EA extract which may be attributed the presence of active biological compounds in methanol extract. Enhanced biofilm reduction of LA-M as compared to LA-EA extract was evident from the altered biomass morphology when observed under the light microscopy (Fig. 7). Moreover, SEM analysis showed typical difference in the phenotype of the test pathogen in the

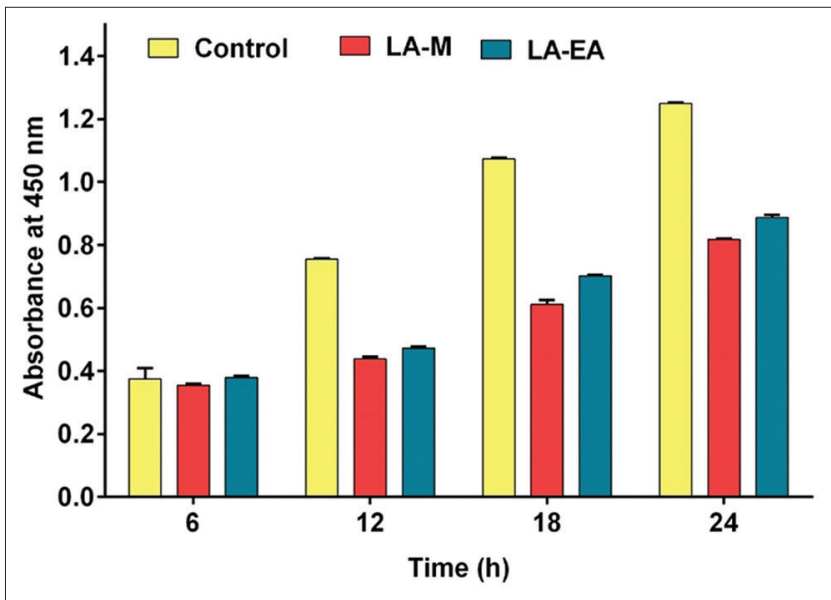

Fig. 6: Metabolic activity assay of LA-M and LA-EA against biofilm forming Vibrio harveyi VA4 at different time points. Values are represented as mean \pm standard error of independent biological triplicate experiments
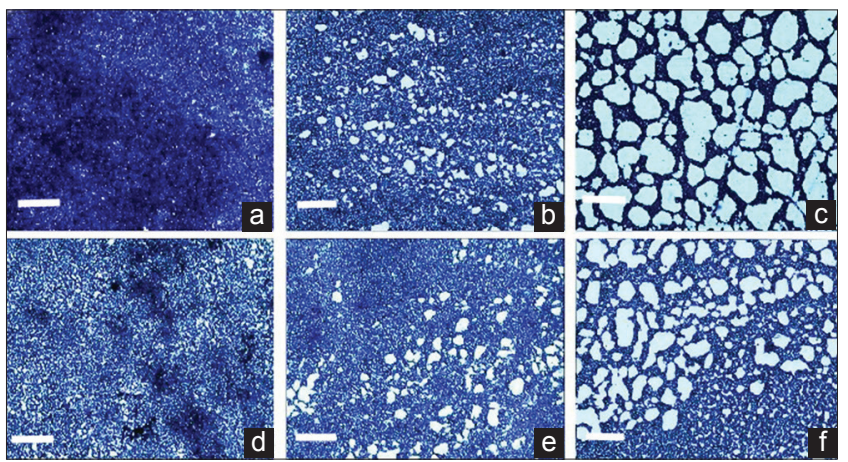

Fig. 7: Biofilm biomass inhibition of Vibrio harveyi VA4 (a and d) untreated control; (b and e) $31.25 \mu \mathrm{g} / \mathrm{ml} \mathrm{LA-M}$ and LA-EA extract treated biofilm, respectively; (c and f) $500 \mu \mathrm{g} / \mathrm{ml} \mathrm{LA}-\mathrm{M}$ and LA-EA treated, respectively. Images were taken at $\times 400$ magnification using Nikon Eclipse E200 series microscope. Scale bar $=20 \mu \mathrm{m}$. 
presence and absence of L. acidissima extracts. Similar results were observed by Alhede et al. [43] who studied the biofilm formation of Gram-negative bacteria on the different substratum and reported that the bioactive components of plant extract result in the hydrophobicity of the biofilm interaction leading to alteration in the structural morphology of the biofilms. Mature biofilms are notably difficult to control and represent a source of infection that is recalcitrant to antibiotics. Planktonic population of the pathogen can be susceptible to a wide range of antibiotics, but sessile cells exhibit phenotypic changes which render antibiotics ineffective against biofilms. Biofilm formation in Vibrio is regulated by cell to cell signaling systems and virulence factors which play a significant role to cause disease in most fishes [44].

In addition, biofilms facilitate chronic wound infections by creating barriers against the immune system of host and antibiotics [45].

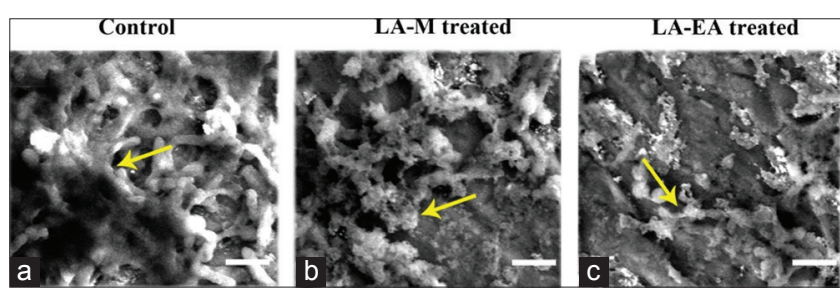

Fig. 8: Scanning Electron Micrographs representing the biofilm biomass reduction of (a) untreated Control; (b) LA-M; and (c)

LA-EA extract treated Vibrio harveyi VA4 biofilms, respectively. Images were taken at $\times \mathbf{2 0 , 0 0 0}$ magnification (using Zeiss, Sigma V Scanning Electron Microscope). Scale bar $=100 \mu \mathrm{m}$
C. violaceum is reported to produce violacein which is regulated by QS process. Inhibition of QS-regulated pigment production is by is often used for the QSI screening studies [46]. As the acyl homoserine lactone (AHL) molecules synthesized by $C$. violaceum differ in their chain length, a wild type (CV ATCC 12724) and a mutant (C026) has been used to assess the QSI activity of LA extracts in the present study. Interestingly, the present study revealed that both the plants extracts were able to inhibit the violacein synthesis irrespective of the C. violaceum strains at BIC without affecting the growth of the cells. Other reports have substantiated the anti-QS activity in plant extracts of Myristica cinnamomea [47], Panax notoginseng [48], Ocimum sanctum, Ananas comosus, Musa paradisiaca, and Manilkara zapota [49] against C. violaceum. Our results are in affirmation with previous studies on bacterial biofilm inhibition by plant extracts [50 52]. Reports have evidently shown that Vibrio forms biofilms in the larval tanks by forming biomass on to the substratum, water lines, and also on recirculation system leading to higher recurrence of infection and fish yield loss [53]. However, complex processes related to genetic and ecological parameters are involved in the biofilm development and establishment mechanisms [54].

\section{CONCLUSION}

The present study is an effort to determine the QSI property of $L$. acidissima against the biofilm forming $V$. harveyi isolated from infected fish. The findings of the present study are in overall consistence with previous studies on the effect of medicinal plants against biofilmforming fish pathogens. Apparently, the present study shows that L. acidissima may possibly be used to control the biofilms of vibrios. However, further studies are needed to explore the effect of Limonia

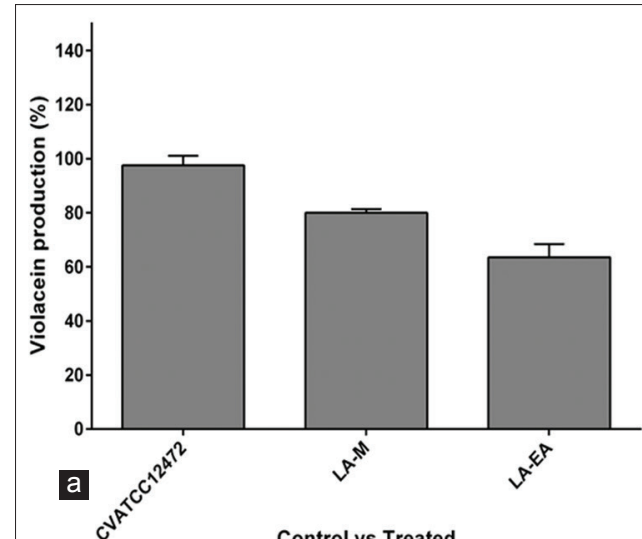

Control vs Treated

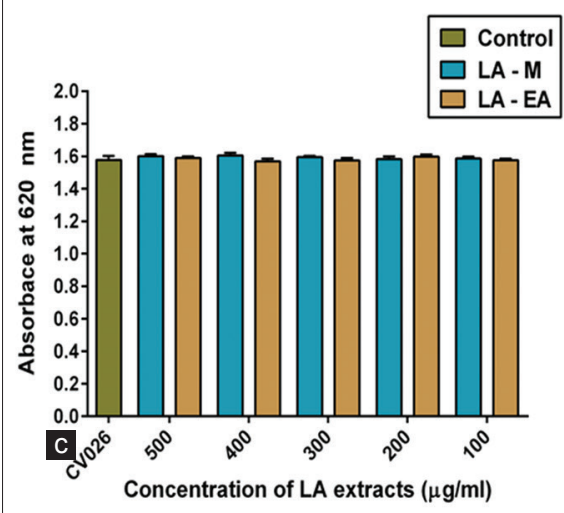

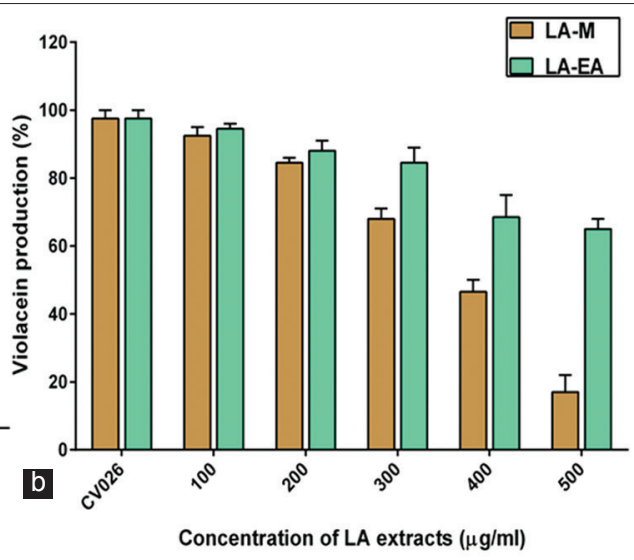

d

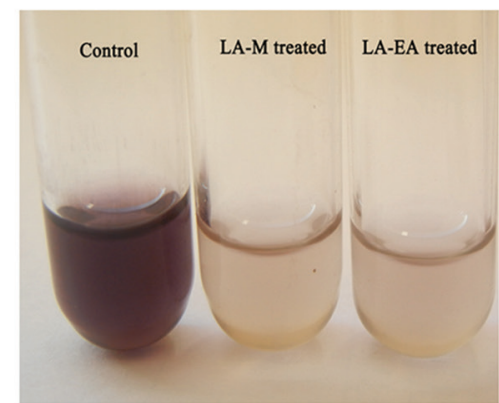

Fig. 9: (a) Inhibition of violacein production by LA solvent extracts at their BIC as compared to the reported strain CV ATCC 12472.

Data are represented as the percentage of violacein production. (b) Inhibition of violacein production by LA-M and LA-EA extracts at different concentrations. Data are represented as the percentage of violacein production. (c) Influence of LA-M and LA-EA on the growth of Chromobacterium violaceum CV026 used as a control in the experiment. Cell density was quantified by measuring the optical density at $620 \mathrm{~nm}$ after $24 \mathrm{~h}$. Mean values of the triplicate independent experiments and standard error are shown. (d) Inhibition of violacein production in CV ATCC 12472 in the presence and absence of LA extracts 
fruit extracts on the expression of virulence genes in the biofilm forming Vibrio.

\section{ACKNOWLEDGMENT}

The authors acknowledge the laboratory facility provided by Karpagam Academy of Higher Education, Coimbatore for the present study.

\section{AUTHOR CONTRIBUTIONS}

SP, RM designed and executed the work, DKS proof read the data.

\section{CONFLICTS OF INTEREST}

None declared.

\section{REFERENCES}

1. Gomez-Gil B, Thompson FL, Thompson CC, Garcia-Gasca A, Roque A, Swings J, et al. Vibrio hispanicus sp. Nov. isolated from Artemia sp. and sea water in Spain. Int J Syst Evol Microbiol 2004;54:261-5.

2. Cabello FC. Heavy use of prophylactic antibiotics in aquaculture: A growing problem for human and animal health and for the environment. Environ Microbiol 2006;8:1137-44.

3. Beyhan S, Yildiz FH. Smooth to rugose phase variation in Vibrio cholerae can be mediated by a single nucleotide change that targets c-di-GMP signalling pathway. Mol Microbiol 2007;63:995-1007.

4. Mielich-Süss B, Lopez D. Molecular mechanisms involved in Bacillus subtilis biofilm formation. Environ Microbiol 2015;17:555-65.

5. Yebra DM, Kiil S, Dam-Johansen K. Antifouling technology-past, present and future steps towards efficient and environmentally friendly antifouling coatings. Prog Org Coat 2004;50:75-104.

6. Bjarnsholt T, Ciofu O, Molin S, Givskov M, Høiby N. Applying insights from biofilm biology to drug development-can a new approach be developed? Nat Rev Drug Discov 2013;12:791-808.

7. Austin B, Zhang XH. Vibrio harveyi: A significant pathogen of marine vertebrates and invertebrates. Lett Appl Microbiol 2006;43:119-24.

8. Miller MB, Bassler BL. Quorum sensing in bacteria. Annu Rev Microbiol 2001;55:165-99.

9. Waters CM, Bassler BL. Quorum sensing: Cell-to-cell communication in bacteria. Annu Rev Cell Dev Biol 2005;21:319-46.

10. Kalia VC. Quorum sensing vs quorum quenching: A battle with no end in sight. Biotechnol Adv 2013;31:224-45.

11. Joint I, Tait K, Wheeler G. Cross-kingdom signalling: Exploitation of bacterial quorum sensing molecules by the green seaweed Ulva. Philos Trans R Soc Lond B Biol Sci 2007;362:1223-33.

12. Dobretsov S, Dahms HU, Yili H, Wahl M, Qian PY. The effect of quorumsensing blockers on the formation of marine microbial communities and larval attachment. FEMS Microbiol Ecol 2007;60:177-88.

13. Twigg MS, Tait K, Williams P, Atkinson S, Cámara M. Interference with the germination and growth of ulva zoospores by quorum-sensing molecules from Ulva-associated epiphytic bacteria. Environ Microbiol 2014; $16: 445-53$

14. Rasmussen TB, Givskov M. Quorum sensing inhibitors: A bargain of effects. Microbiology 2006;152:895-904.

15. Skindersoe ME, Ettinger-Epstein P, Rasmussen TB, Bjarnsholt T, de Nys R, Givskov M, et al. Quorum sensing antagonism from marine organisms. Mar Biotechnol (NY) 2008;10:56-63.

16. Cushnie TP, Lamb AJ. Recent advances in understanding the antibacterial properties of flavonoids. Int $\mathrm{J}$ Antimicrob Agents 2011:38:99-107.

17. Nazzaro F, Fratianni F, Coppola R. Quorum sensing and phytochemicals. Int J Mol Sci 2013;14:12607-19.

18. Vattem DA, Mihalik K, Crixell SH, McLean RJ. Dietary phytochemicals as quorum sensing inhibitors. Fitoterapia 2007;78:302-10.

19. Niu C, Afre S, Gilbert ES. Subinhibitory concentrations of cinnamaldehyde interfere with quorum sensing. Lett Appl Microbiol 2006;43:489-94

20. Khan MS, Zahin M, Hasan S, Husain FM, Ahmad I. Inhibition of quorum sensing regulated bacterial functions by plant essential oils with special reference to clove oil. Lett Appl Microbiol 2009;49:35460 .

21. Dineshbabu J, Srinivasan P, Manimekalai K, Guna G, Darsini DT. Use of traditional medicinal plants against the biofilm forming Streptococcus pyogenes isolated from upper respiratory tract. Int J Pharm Bio Sci 2015;6:464-79.

22. Darsini DT, Srinivasan P, Guna G, Manimekalai K, Dineshbabu J. In vitro anti-biofilm activity of Piper longum and Piper nigrum against clinical isolates of Streptococcus pyogenes, isolated from pharyngitis patients. Int Res J Pharm 2015;6:122-32

23. Darsini DT, Maheshu V, Vishnupriya M, Nishaa S, Sasikumar JM. Antioxidant potential and amino acid analysis of underutilized tropical fruit Limonia acidissima L. Free Rad Antiox 2013;3:S62-9.

24. Srinivasan P, Darsini DT, Maheshu V, Castro J, Dineshbabu J, Manimekalai K. Limonia acidissima L. (wood apple) as feed additive enhanced growth performance, immune response and disease resistance of Indian major carp, Catla catla (Ham.) against Aeromonas hydrophila infection. Int Res J Pharm 2015;6:143-52.

25. Srinivasan P, Dineshbabu J, Manimekalai K, Castro J, Darsini DT. Influence of Limonia acidissima L. Against the biofilm forming Aeromonas hydrophila isolated from fresh water fishes. J Biochem Tech 2015;6:910-21.

26. Jawetz E, Melnick JI, Adelberg EA. Medical Microbiology. $24^{\text {th }}$ ed. U.S.A: Appleton and Lange; 2007.

27. Macc Fadin JK. Biochemical Test for Identification of Medical Bacteria. $3^{\text {rd }}$ ed. Philadelphia, PA, Baltimor, New York: Lippincott Williams and Winkins, Awolter Klumer Company; 2000.

28. Stackebrandt E, Murray RG, Trüper HG. Proteobacteria classis nov. a name for the phylogenetic taxon that includes the "purple bacteria and their relatives". Int J Syst Evol Microbiol 1988;38:321-5.

29. Clinical and Laboratory Standards Institute. Performance Standards for Antimicrobial Susceptibility Testing: Seventeenth Informational Supplement: M100-S17. Wayne, Philadelphia, PA, USA: CLSI; 2007.

30. Gavín R, Merino S, Altarriba M, Canals R, Shaw JG, Tomás JM, et al. Lateral flagella are required for increased cell adherence, invasion and biofilm formation by Aeromonas spp. FEMS Microbiol Lett 2003;224:77-83.

31. Husain FM, Ahmad I. Doxycycline interferes with quorum sensingmediated virulence factors and biofilm formation in gram-negative bacteria. World J Microbiol Biotechnol 2013;29:949-57.

32. Bomchil N, Watnick P, Kolter R. Identification and characterization of a Vibrio cholerae gene, mbaA, involved in maintenance of biofilm architecture. J Bacteriol 2003;185:1384-90.

33. Choo JH, Rukayadi Y, Hwang JK. Inhibition of bacterial quorum sensing by vanilla extract. Lett Appl Microbiol 2006;42:637-41.

34. Haldar S, Chatterjee S, Sugimoto N, Das S, Chowdhury N, Hinenoya A, et al. Identification of Vibrio campbellii isolated from diseased farmshrimps from South India and establishment of its pathogenic potential in an Artemia model. Microbiology 2011;157:179-88.

35. Lewis K. Persister cells, dormancy and infectious disease. Nat Rev Microbiol 2007;5:48-56.

36. Williams P. Quorum sensing, communication and cross-kingdom signalling in the bacterial world. Microbiology 2007;153:3923-38.

37. You J, Xue X, Cao L, Lu X, Wang J, Zhang L, et al. Inhibition of vibrio biofilm formation by a marine actinomycete strain A66. Appl Microbiol Biotechnol 2007;76:1137-44

38. Shipra P, Gouri S, Gupta RK. Evaluation of nutritional, phytochemical, antioxidant and antibacterial activity of exotic fruit Limonia acidissima. J Pharm Phytochem 2014;3:81-8.

39. Ilango K, Chitra V. Wound healing and anti-oxidant activities of the fruit pulp of Limonia acidissima Linn. (Rutaceae) in rats. Trop J Pharm Res 2010;9:223-30.

40. Ahamed SM, Swamy SK, Jayaverra KN, Rao JV, Kumar VS. Antiinflammatory antipyretic and analgesic activity of methanolic extract of Feronia limonia fruit pulp. Pharmacol online 2008;3:852-7.

41. Mishra P, Samanta M, Mohanty S, Maiti NK. Characterization of Vibrio species isolated from freshwater fishes by ribotyping. Indian J Microbiol 2010;50:101-3.

42. Pettit RK, Weber CA, Kean MJ, Hoffmann H, Pettit GR, Tan R, et al. Microplate alamar blue assay for Staphylococcus epidermidis biofilm susceptibility testing. Antimicrob Agents Chemother 2005;49:2612-7.

43. Alhede M, Kragh KN, Qvortrup K, Allesen-Holm M, van Gennip M, Christensen LD, et al. Phenotypes of non-attached pseudomonas Aeruginosa aggregates resemble surface attached biofilm. PLoS One 2011;6:e27943.

44. Khajanchi BK, Fadl AA, Borchardt MA, Berg RL, Horneman AJ, Stemper ME, et al. Distribution of virulence factors and molecular fingerprinting of Aeromonas species isolates from water and clinical samples: Suggestive evidence of water-to-human transmission. Appl Environ Microbiol 2010;76:2313-25.

45. Thurlow LR, Hanke ML, Fritz T, Angle A, Aldrich A, Williams SH, et al. Staphylococcus aureus biofilms prevent macrophage phagocytosis and attenuate inflammation in vivo. J Immunol 2011;186:6585-96.

46. McClean KH, Winson MK, Fish L, Taylor A, Chhabra SR, Camara 
M, et al. Quorum sensing and Chromobacterium violaceum: Exploitation of violacein production and inhibition for the detection of N-acylhomoserine lactones. Microbiology 1997;143:3703-11.

47. Szczepanski S, Lipski A. Essential oils show specific inhibiting effects on bacterial biofilm formation. Food Control 2014;36:224-9.

48. Koh KH, Tham FY. Screening of traditional Chinese medicinal plants for quorum-sensing inhibitors activity. J Microbiol Immunol Infect 2011;44:144-8.

49. Song Z, Kong KF, Wu H, Maricic N, Ramalingam B, Priestap H, et al. Panax ginseng has anti-infective activity against opportunistic pathogen Pseudomonas aeruginosa by inhibiting quorum sensing, a bacterial communication process critical for establishing infection. Phytomedicine 2010;17:1040-6.
50. Yano Y, Satomi M, Oikawa H. Antimicrobial effect of spices and herbs on vibrio parahaemolyticus. Int J Food Microbiol 2006;111:6-11.

51. Kavanaugh NL, Ribbeck K. Selected antimicrobial essential oils eradicate Pseudomonas spp. and Staphylococcus aureus biofilms. Appl Environ Microbiol 2012;78:4057-61.

52. Srinivasan P, Dineshbabu J, Manimekalai K, Darsini DT. Spectroscopic analysis and antibacterial efficacy of bioactive compounds from Limonia acidissima L. Fruit extract against clinical pathogens. Int J Pharm Pharm Sci 2015;7:81-5.

53. Mandabi A, Ganin H, Meijler MM. Synergistic activation of quorum sensing in Vibrio harveyi. Bioorg Med Chem Lett 2015;25:3966-9.

54. Kjelleberg $\mathrm{S}$, Molin $\mathrm{S}$. Is there a role for quorum sensing signals in bacterial biofilms? Curr Opin Microbiol 2002;5:254-8. 